\title{
Intraguild predation on Trichogramma chilonis Ishii (Hymenoptera: Trichogrammatidae) by the generalist predator Geocoris ochropterus Fieber (Hemiptera: Geocoridae)
}

\author{
Richa Varshney ${ }^{1 *}$ and Chandish R. Ballal ${ }^{2}$
}

\begin{abstract}
Intraguild predation (IGP) is common in food web when two natural enemies share the same resources and prey. It may affect the success or failure of a biological control attempt. The role of intraguild predation by Geocoris ochropterus Fieber (Heteroptera: Geocoridae) on Trichogramma chilonis Ishii (Hymenoptera: Trichogrammatidae) developed on eggs of Helicoverpa armigera (Hubner) (Lepidoptera: Noctuidae) and Corcyra cephalonica (Stainton) (Lepidoptera: Pyralidae) was evaluated under laboratory conditions. In choice experiments, both fifth instar nymph and adult of $G$. ochropterus preferred to predate on unparasitized eggs of $\mathrm{H}$. armigera and C. cephalonica over parasitized eggs. In no-choice experiments, G. ochropterus nymph consumed 58 and $67 \%$ of unparasitized $H$. armigera and C. cephalonica eggs, compared to 3.33 and $7.38 \%$ of parasitized ones. A similar trend was observed in no-choice experiments with adult predator. Additional semi-field and field studies are required to explicate the consequences and intensity of intraguild predation in agro-ecosystem.
\end{abstract}

Keywords: Intraguild predation, Geocoris ochropterus, Trichogramma chilonis, Parasitized eggs, Preference

\section{Background}

The big-eyed bugs, Geocoris spp. (Hemiptera: Geocoridae) are small generalist insect omnivores which prey upon several insect and mite pests (Schuman et al. 2013). In India, Geocoris ochropterus Fieber is a very common species found in cotton, lucerne, maize, sunflower, tea, and other fruit and flowering plants. It was observed feeding on Helicoverpa armigera (Hubner) (Lepidoptera: Noctuidae) eggs (personal observation). In India, $H$. armigera is a polyphagous pest attacking several crops including vegetable, pulses, and cotton. Trichogramma chilonis Ishii (Hymenoptera: Trichogramatidae) is the most popularly used egg parasitoid, which is released primarily against several lepidopteran pests including the notorious and

\footnotetext{
* Correspondence: richavarshney84@gmail.com

'Department of Insect Ecology, ICAR- National Bureau of Agricultural Insect Resources, P.B no.2491, H.A. Farm Post, Bellary road, Hebbal,

Bengaluru-560024, Karnataka, India

Full list of author information is available at the end of the article
}

polyphagous pest, $H$. armigera infesting crops (Gupta and Ballal 2007). When natural enemies share the same niche, resources, and common prey species, they might engage in intraguild predation (IGP), wherein one natural enemy consumes the other (Holt and Polis 1997). IGP may have a negative (Rosenheim 2005) or a positive effect (Gardiner and Landis 2007) on biological control. Thus, it is very much warranted to select species combinations on the basis of their positive interaction so that they can further be used synergistically to enhance the efficacy of biological control agents.

Combined releases of parasitoids and predators were found to be effective in managing pests of several crops. Adnan-Babi and Pintureau (2002) observed that Trichogramma principium Sugonyaeu and Sorokina and Chrysoperla carnea (Stephens) (Neuroptera: Chrysopidae) could be successfully released together for management of cotton bollworms in Syria. Combined releases of Trichogramma sp. and C. carnea against 
Heliothis spp. (Lepidoptera: Noctuidae) on cotton were made in the USA (Ridgway et al. 1973). T. chilonis and C. carnea against cotton bollworms and sucking pests in India and Lysiphlebus testaceipes (Cresson) (Hymenoptera: Aphidiinae) and Hippodamia convergens Guérin-Méneville (Coleoptera: Coccinellidae) against cotton aphids in cotton (Colfer and Rosenheim 2001) are some of the successful examples.

Combined use of T. chilonis and G. ochropterus is a strategy being considered for management of lepidopteran insect pests in polyhouses in India. Therefore, IGP is considered as an important factor deciding the success or failure of biological control agents (Rosenheim and Harmon 2006). Velasco-Hernandez et al. (2013) reported that Geocoris punctipes (Say) had a significant preference for non-parasitized Trialeurodes vaporariorum Westwood (Hemiptera: Aleyrodidae) nymphs in choice tests. However, Naranjo (2007) reported that three generalist predators, G. punctipes (Say), Orius insidiosus (Say) (Hemiptera: Anthocoridae), and Hippodamia convergens GuerinMeneville preferred parasitized Bemisia tabaci (Gennadius) (Hemiptera: Aleyrodidae) by Eretmocerus sp. nr. emiratus (Hymenoptera: Aphelinidae) or could not discriminate between parasitized and non-parasitized nymphs.

Studies on the predation by G. ochropterus on $H$. armigera eggs are scarce, and there is no information available on IGP by G. ochropterus on H. armigera eggs parasitized by $T$. chilonis. The purpose of this study was to evaluate the prey preference of adult and mature nymph of $G$. ochropterus for unparasitized and T. chilonis parasitized lepidopteran eggs thus to predict the combined field releases of G. ochropterus and trichogrammatids.

\section{Materials and methods}

\section{Insect cultures and rearing}

Initial cultures of Corcyra cephalonica (Stainon) (Lepidoptera: Pyralidae) (National Accession number: NBAII-MP-PYR-01), $H$. armigera (National Accession number: NBAII-MP-NOC-01), and T. chilonis (National Accession Number: NBAII-MP-TRI-13a) were obtained from the mass production unit at the National Bureau of Agricultural Insect Resources, Bangalore, India. Eggs of $C$. cephalonica and $H$. armigera were glued on cards and exposed separately to $T$. chilonis females in the ratio of 30 eggs per female parasitoid for $24 \mathrm{~h}$ in $15 \times 1.5 \mathrm{~cm}$ test tubes (Gupta and Ballal 2007). G. ochropterus was collected from maize field and reared in the laboratory on beans and C. cephalonica eggs and H. armigera for three generations to acclimatize under laboratory conditions before initiating the experiments. Methodology for $G$. ochropterus rearing was followed as mentioned by Varshney and Ballal (2017). Newly emerged fifth instar nymph and 1- to 2-week-old adult predator females were used in experiments (as adult requires a pre-mating period of 4 to
5 days and can live for more than 8 weeks (personal observation). All the insects under study were maintained, and IGP experiments were conducted at $26 \pm 2{ }^{\circ} \mathrm{C}, 65 \pm 2 \%$ relative humidity with a photoperiod of 12:12 (L:D).

\section{Assessment of IGP on Corcyra cephalonica (Stainon) No-choice test}

In no-choice experiment, 30 6-day-old parasitized (parasitized eggs turn black in color when they are 6 days old which confirms parasitism) and fresh unparasitized C. cephalonica were pasted on separate cards. Each card was kept separately in a smallventilated round plastic box $(7.5 \mathrm{~cm}$ diameter and $2.5 \mathrm{~cm}$ height); the floor of the container was covered with a piece of tissue paper. Newly emerged fifth instar G. ochropterus nymph (previously starved for $24 \mathrm{~h}$ ) was introduced at the rate of one per box. The same set-up was repeated with 8-day-old G. ochropterus adult (previously starved for $24 \mathrm{~h}$ ). During the starvation period, cotton swab soaked in a tap water was provided to the nymph and adult stages of the predator.

The following treatments set up under no-choice were as follows:

T1-30 unparasitized C. cephalonica eggs + 1 G.
ochropterus mature nymph
T2-30 parasitized C. cephalonica eggs + 1 G.
ochropterus mature nymph
T3-30 unparasitized C. cephalonica eggs + 1 G.
ochropterus adult
T4-30 parasitized C. cephalonica eggs + 1 G.
ochropterus adult

Both nymphs and adults were allowed to forage for $24 \mathrm{~h}$ after the introduction of the predator into the arena. After $24 \mathrm{~h}$, eggs were observed under a stereomicroscope (Olympus SZX15) and the number of consumed eggs (i.e., based on empty eggs with ruptured chorion) was recorded to find out the predation level of G. ochropterus on parasitized and unparasitized $C$. cephalonica eggs in a no-choice situation.. Each treatment was replicated 14 times.

\section{Choice test}

In the choice test, 30 6-day-old parasitized eggs and 30 fresh eggs of C. cephalonica were pasted on separate cards and kept together in small plastic ventilated round boxes $(7.5 \mathrm{~cm}$ diameter and $2.5 \mathrm{~cm}$ height). One predator each (nymph or adult) of G. ochropterus was released into each box holding the parasitized and unparasitized eggs.

The following were the treatments under the choice test: 
T1: 30 unparasitized +30 parasitized C. cephalonica eggs +1 G. ochropterus mature nymph

T2: 30 unparasitized +30 parasitized C. cephalonica eggs +1 G. ochropterus adult

Each treatment was replicated 14 times. Observations were recorded after $24 \mathrm{~h}$ on the number of eggs damaged by nymphs and adults of predator.

\section{Assessment of IGP on Helicoverpa armigera (Hubner)}

The same experimental methodology for $H$. armigera eggs were carried out as done in the IGP with C. cephalonica eggs.

Additionally, preference index of prey type was evaluated by calculating Manly's index of preference (Manly 1974; Meyling et al. 2004) for each replicate

$$
\beta 1=\frac{\log \left(\frac{e 1}{A 1}\right)}{\log \left(\frac{e 1}{A 1}\right)+\log \left(\frac{e 2}{A 2}\right)}
$$

where $\beta 1$ is the preference for prey type $1, e 1$ is the number of prey remaining after experimentation, and $A 1$ is the number of prey offered. An index value close to 0.5 indicates that the predator shows no preference for a given prey type, a value close to 1 indicates preference for prey type 1 , and a value close to 0 indicates preference for prey type 2 (Meyling et al. 2004). In the present case, unparasitized eggs were chosen as prey type 1 . Manly's index applies to experimental situations where killed prey are not replaced (Manly 1974; Sherrat and Harvey 1993; Meyling et al. 2004). Cock (1978) pointed out this index as the only method that takes into account lower prey density throughout the trial development. The value of preference index $(\beta 1)$ varies from 0 to 1 . One-sample $t$ tests were used to compare the experimentally observed Manly's index for unparasitized eggs and a value of 0.5 to test the null hypothesis that the predator selected prey at random.

\section{Data analysis}

In no-choice test, one-way ANOVA was used to test for differences in predation rates on the two types of prey by predator. The effect of prey (parasitized and unparasitized) and predator stage (nymph and adult) together with their interaction was also studied using univariate general linear model (two-way ANOVA) with prey and predator stage together with their interaction as fixed factors.

Free-choice bioassay data were analyzed using an independent $t$ test comparing the mean number of parasitized and unparasitized prey consumed by $G$. ochropterus.

\section{Results and discussion}

\section{No-choice test}

When parasitized and unparasitized eggs of $H$. armigera were provided separately to G. ochropterus nymph, it consumed significantly more numbers of unparasitized than parasitized eggs $\left(F_{1,27}=64.8, P<0.0001\right)$. The mean number $( \pm \mathrm{SE})$ of eggs was $17.3 \pm 2.01$ and $1.00 \pm 0.28$ for unparasitized and parasitized $H$. armigera eggs, respectively. Similar trend with higher preference for unparasitized eggs was observed in case of adult G. ochropterus which consumed $26.25 \pm 0.99$ and $4.28 \pm 0.24$ unparasitized and parasitized $H$. armigera eggs, respectively $\left(F_{1,27}=486.6, \quad P<0.0001\right)$. Two-way ANOVA indicates that predation rate was significantly affected by prey egg type (parasitized and unparasitized $) \quad\left(F_{1,56}=292.86, \quad P<0.0001\right)$, predator stage (mature nymph and adult) $\left(F_{1,56}=31.6, P<0.0001\right)$, and the interaction between prey egg type and predator stage $\left(F_{1,56}=7.46, P=0.009\right)$.

When G. ochropterus nymph had access to unparasitized and parasitized C. cephalonica eggs, a nymph consumed $20.28 \pm 1.43$ of the unparasitized eggs and $2.21 \pm$ 0.50 of the parasitized eggs with a significant difference $\left(F_{1,27}=286.8, P<0.0001\right)$. However, adult predator consumed 25.4 \pm 1.05 unparasitized eggs and $6.14 \pm 0.86$ parasitized eggs $\left(F_{1,27}=199.6, P<0.0001\right)$. When eggs of C. cephalonica were offered as prey, the predation rate was significantly affected by prey type (parasitized and unparasitized) $\left(F_{1,56}=464.8, P<0.0001\right)$, predator stage (mature nymph and adult) $\left(F_{1,56}=27.4, P<0.0001\right)$ but not by the interaction between prey and predator stage $\left(F_{1,56}=0.491, P=0.487\right)$ (two-way ANOVA).

\section{Choice test}

G. ochropterus nymph consumed significantly more unparasitized $H$. armigera eggs than parasitized eggs when nymph was offered both types of eggs in a choice arena $(t=-22.38, \quad \mathrm{df}=19.3, \quad P<0.01)$. This result was confirmed by the mean value of the preference index ( $\mathrm{PI}=0.98 \pm 0.005)$, indicating that $G$. ochropterus nymph had a significant preference for consuming unparasitized eggs (Table 1).

Similarly, G. ochropterus adult had a significant preference for unparasitized $H$. armigera eggs in comparison to parasitized eggs in a choice arena $(t=-10.02$, $\mathrm{df}=13.9, P<0.01)$. It is clear from the preference index that G. ochropterus adult exhibited a significant preference for unparasitized $H$. armigera eggs ( $\mathrm{PI}=0.95 \pm 0.003$ ).

When $C$. cephalonica eggs were used as prey, both nymph and adult of $G$. ochropterus exhibited a significant preference for unparasitized eggs relative to parasitized eggs when both types of eggs were available in a choice arena. G. ochropterus nymph consumed higher unparasitized eggs compared to parasitized eggs $(t=-19.8, \mathrm{df}=17.37, P<0.01)$. This is evident 
Table 1 Numbers of Helicoverpa armigera and Corcyra cephalonica eggs consumed and Manly's index of preference for nymph and adult of Geocoris ochropterus given a choice of unparasitized and parasitized eggs by Trichogramma chilonis

\begin{tabular}{llllll}
\hline Lepidopteran egg & Predator stage & $\begin{array}{l}\text { No. of unparasitized eggs } \\
\text { consumed (mean } \pm \mathrm{SE} \text { ) }\end{array}$ & $\begin{array}{l}\text { No. of parasitized eggs } \\
\text { consumed (mean } \pm \mathrm{SE})\end{array}$ & $\begin{array}{l}\text { Manly's index of preference } \\
\mathrm{df}=13, P<0.001\end{array}$ \\
\hline Helicoverpa armigera & G. ochropterus fifth instar & $20.7 \pm 0.76$ & $1.64 \pm 0.38$ & $0.97 \pm 0.01$ & 80.1 \\
& G. ochropterus adult & $26.57 \pm 1.14$ & $3.28 \pm 0.22$ & $0.95 \pm 0.004$ & 118.3 \\
Corcyra cephalonica & G. ochropterus fifth instar & $21.29 \pm 0.93$ & $1.35 \pm 0.39$ & $0.96 \pm 0.01$ & 53.6 \\
& G. ochropterus adult & $23.7 \pm 1$ & $2.07 \pm 0.54$ & $0.94 \pm 0.01$ & 47.2 \\
\hline
\end{tabular}

${ }^{a}$ One-sample $t$ tests by comparing Manly's index for non-parasitized eggs and a value of 0.5 to test the null hypothesis that the predator selected prey at random

with a preference index $(\mathrm{PI}=0.96 \pm 0.009)$ which indicated that G. ochropterus nymph had a significant preference for unparasitized C. cephalonica eggs (Table 1).

A similar trend was observed in the case of G. ochropterus adult, which also showed a significant preference for unparasitized C. cephalonica eggs (PI $=0.94 \pm 0.009)$.

Total consumption of parasitized and unparasitized eggs of both $C$. cephalonica and $H$. armigera by $G$. ochropterus nymph and adult in choice and no-choice tests has been depicted in Fig. 1. It is also clear that although nymph and adult of $G$. ochropterus consumed significantly more parasitized eggs of $C$. cephalonica in the no-choice test compared to the choice one $(t=3.65, \mathrm{df}=38.2, P=0.001)$ but in case of $H$. armigera, there is no significant difference in consumption of parasitized $H$. armigera eggs $(t=0.39$, $\mathrm{df}=49.7, P>0.05)$ in both tests.

In the present study, daily observations of nymphal and adult treatments revealed that although G. ochropterus fed on few parasitized eggs, it could not consume more parasitized eggs. Non-preference for parasitized eggs has been reported in the case of several predators. Oliveira et al. (2004) reported that predatory pentatomid, Podisus maculiventris (Say) (Hemiptera: Pentatomidae), showed a greater preference for unparasitized eggs of Ephestia kuehniella Zeller (Pyralidae: Lepidoptera) when compared to eggs parasitized by $T$. brassicae Bezdenko. H. zea (Boddie) eggs parasitized by $T$. pretiosum Riley were not accepted by Chrysoperla externa (Hagen) (Ciociola-Junior et al. 1999). Anthocorid predators Xylocoris flavipes (Reuter) (Hemiptera: Anthocoridae) and $O$. insidiosus had a greater preference for unparasitized prey eggs in comparison to those parasitized by $T$. pretiosum (Ruberson and Kring 1991). Gupta and Ballal (2007) reported significantly higher preference for unparasitized eggs of $H$. armigera and C. cephalonica by $O$. tantillus (Motschulsky) and Blaptostethus pallescens Poppius (Hemiptera: Anthocoridae). Coccinella septempunctata Linnaeus and Harmonia axyridis Pallas (Coleoptera: Coccinellidae) preferred non-parasitized Aphis glycines Matsumura (Hemiptera: Aphididae) over mummified aphids (Xue et al. 2012). Similar result has been documented by Snyder et al. (2004) who reported that $H$. axyridis can complement aphid biocontrol by the parasitoid Aphelinus asychis Walker (Hymenoptera: Aphelinidae), rather than disrupting control through intraguild predation.

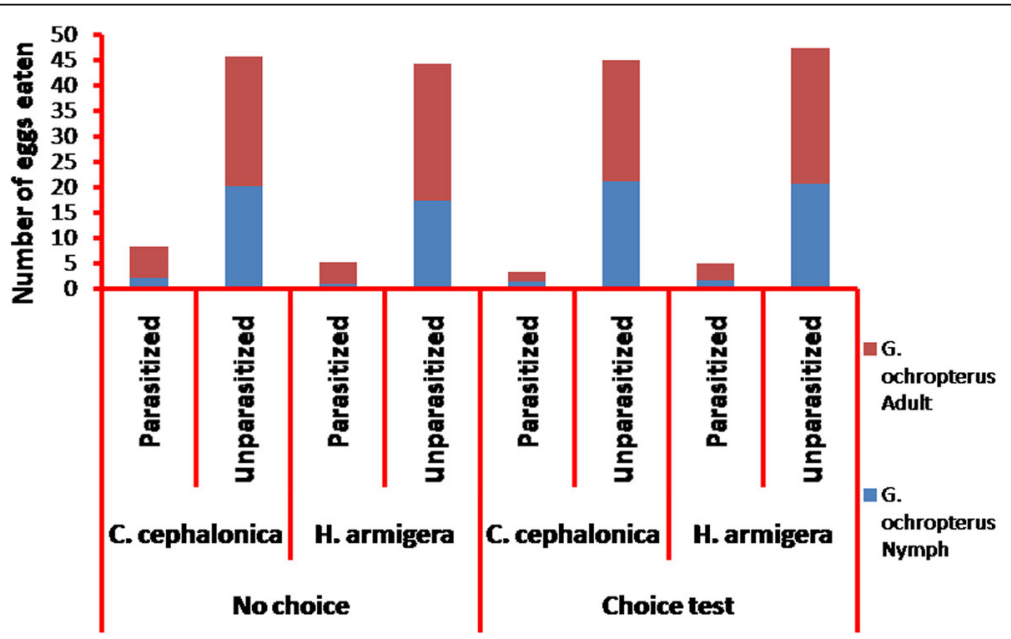

Fig. 1 Total number of parasitized and unparasitized Helicoverpa armigera and Corcyra cephalonica eggs consumed by nymph and adult of Geocoris ochropterus in no-choice and choice tests 
Four-day-old parasitized eggs contain third instar of Trichogramma parasitoid which deposit dark melanin granules on the inner surface of egg chorion causing the eggs to turn black and hard. The hardness of the chorion of the parasitized eggs on day 6 may also be due to the formation of pupal stage at this time. This could be a reason for lower preference of parasitized eggs by this predator. There are some other factors, which may influence IG-predator preferences, such as hardening the cuticle (Chailleux et al. 2013), physiological/chemical changes (Gelman et al. 2002) in parasitized eggs, and prey species (Roger et al. 2000). Further studies are required to understand the potential reasons for non-acceptance of parasitized eggs by the geocorid predator. There are reports describing the negative effect of IGP on biological control program (Raymond et al. 2000; Snyder and Ives 2001), while there are other reports where positive effect of IGP was observed leading to successful control of pest population (Colfer and Rosenheim 2001; Xue et al. 2012).

Before making combined releases of a predator and a parasitoid, besides studying possible IGP by the general predator on the parasitoid, it would be useful to study the possibility of the parasitoid parasitizing the eggs and other stages of the predator. Further studies focused on the effect of age of the parasitized eggs on the feeding preference of G. ochropterus are warranted. Additional semi-field and field studies are required to explicate the consequences and intensity of IGP in agro-ecosystem as in field conditions, IGP is influenced by many factors such as habitat complexity, multispecies interaction, and escape possibilities (Velasco-Hernandez et al. 2013). In complex ecosystem, the effects of IGP are expected to be weaker than in simple laboratory contexts (Janssen et al. 2007) because there are many existing preys on which a general predator can feed.

\section{Conclusions}

In conclusion, present studies indicate that combined releases of $G$. ochropterus and $T$. chilonis may be feasible but glass house and field studies are warranted to confirm the usefulness of such combined release of natural enemies to improve the biological control programs targeting lepidopteran pests.

\section{Acknowledgements}

The authors are grateful to the Indian Council of Agricultural Research, India, for the facilities provided for conducting the study. The authors are also grateful to Mrs. Shashikala Kadam, CTO, NBAIR and Dr. Y. Lalitha ACTO, NBAIR for providing all insect cultures except G. ochropterus.

\section{Authors' contributions}

RV participated in the design of the study, conducted experiments, preparation of manuscript and performed the statistical study. CRB contributed in design of study and preparation of manuscript. Both authors read and approved the final manuscript.

Competing interests

The authors declare that they have no competing interests.

\section{Publisher's Note}

Springer Nature remains neutral with regard to jurisdictional claims in published maps and institutional affiliations.

\section{Author details}

${ }^{1}$ Department of Insect Ecology, ICAR- National Bureau of Agricultural Insect Resources, P.B no.2491, H.A. Farm Post, Bellary road, Hebbal, Bengaluru-560024, Karnataka, India. ${ }^{2}$ Director, ICAR-National Bureau of Agricultural Insect Resources, P.B no.2491, H.A. Farm Post, Bellary road, Hebbal, Bengaluru-560024, Karnataka, India.

Received: 2 October 2017 Accepted: 6 December 2017

Published online: 30 January 2018

\section{References}

Adnan-Babi MA-N, Pintureau B (2002) A study on the effect of Trichogramma pricipium release on cotton bollworm and the chrysopid predator Chrysoperla carnea in Syrian cotton fields. Arab Journal of Plant Protection 20:59-61

Chailleux A, Bearez P, Pizzol J, Amiens-Desneux E, Ramirez-Romero R (2013) Potential for combined use of parasitoids and generalist predators for biological control of the key invasive tomato pest Tuta absoluta. J Pest Sci 86:533-541

Ciociola-Junior Al, Ciociola Al, Cruz I (1999) Effect of natural enemies on non-parasitized and parasitized Helicoverpa zea (Boddie, 1850) eggs by Trichogramma pretiosum (Riley, 1879). Ciencia e Agrotecnologia 22: 290-294

Cock M (1978) The assessment of preference. J Anim Ecol 47:805-816

Colfer RG, Rosenheim JA (2001) Predation on immature parasitoids and its impact on prey suppression. Oecologia 126:292-304

Gardiner MM, Landis DA (2007) Impact of intraguild predation by adult Harmonia axyridis (Coleoptera: Coccinellidae) on Aphis glycines (Hemiptera: Aphididae) biological control in cage studies. Biol Control 40:386-395

Gelman DB, Blackburn MB, Hu JS (2002) Timing and ecdysteroid regulation of the molt in last instar greenhouse whiteflies (Trialeurodes vaporariorum). J Insect Physiol 48:63-73

Gupta T, Ballal CR (2007) Feeding preference of anthocorid predators for parasitized and unparasitized eggs of Corcyra cephalonica (Stainton) and Helicoverpa armigera (Hubner). J Biol Control 21:73-78

Holt RD, Polis GA (1997) A theoretical framework for intraguild predation. Am Nat 149:745-764

Janssen A, Sabelis MW, Magalhaes S, Montserrat M, Van der Hammen T (2007) Habitat structure affects intraguild predation. Ecology 88:2713-2271

Manly BJF (1974) A model for certain types of selection experiments. Biometrics 30:281-294

Meyling NV, Enkegaard A, Brodsgaard H (2004) Intraguild predation by Anthocoris nemorum (Heteroptera: Anthocoridae) on the aphid parasitoid Aphidius colemani (hymenoptera: Braconidae). Biocontrol Sci Tech 14:627-630

Naranjo SE (2007) Intraguild predation on Eretmocerus sp. nr. emiratus, a parasitoid of Bemisia tabaci, by three generalist predators with implications for estimating the level and impact of parasitism. Biocontrol Sci Tech 17:605-622

Oliveira HN, De- Clerca P, Zanuncio JC, Pratissoli D, Pedruzzi EP (2004) Nymphal development and feeding preference of Podis/ls maculiventris (Heteroptera: Pentatomidae) on eggs of Ephestia kuehniella (Lepidoptera: Pyralidae) unparasitized or not by Trichogramma brassicae (Hymenoptera: Trichogrammatidae). Braz J Biol 64:459-463

Raymond B, Darby AC, Douglas AE (2000) Intraguild predators and the spatial distribution of a parasitoid. Oecologia 124:367-372

Ridgway RL, Morrison RK, Kinzer RE, Stinner RE, Reeves BG (1973) Programmed release of parasites and predators for control of Heliothis spp on cotton. In: Proceedings of the Beltwide cotton production research conferences. National cotton council, USA, pp 92-94 
Roger C, Coderre D, Boivin G (2000) Differential prey utilization by the generalist predator Coleomegilla maculata lengi according to prey size and species. Entomologia Experimentalis et Applicata 94:3-13

Rosenheim JA (2005) Intraguild predation of Orius tristicolor by Geocoris spp. and the paradox of irruptive spider mite dynamics in California cotton. Biol Control 32:172-179

Rosenheim JA, Harmon JP (2006) The influence of intraguild predation on the suppression of a shared prey population: an empirical reassessment. In: Brodeur J, Boivin G (eds) Trophic and guild interactions in biological control. Springer, The Netherlands, pp 1-2

Ruberson JR, Kring JT (1991) Predation of Trichogramma pretiosum by the anthocorid Orius insidiosus. Colloques de I-INRA 56:41-46

Schuman MC, Kessler D, Baldwin IT (2013) Ecological observations of native Geocoris pallens and G. punctipes populations in the Great Basin desert of southwestern Utah. Psyche 2013:1-11

Sherrat TN, Harvey IF (1993) Frequency-dependent food selection by arthropodes: a review. Biol J Linn Soc 48:167/186

Snyder WE, Ballard SN, Yang S, Clevenger GM, Miller TD, Ahn JJ, Hatten TD, Berryman AA (2004) Complementary biocontrol of aphids by the ladybird beetle Harmonia axyridis and the parasitoid Aphelinus asychis on greenhouse roses. Biol Control 30:229-235

Snyder WE, Ives AR (2001) Generalist predators disrupt biological control by a specialist parasitoid. Ecology 82:705-716

Varshney R, Ballal CR (2017) Biological, morphological and life table parameters of the predator, Geocoris ochropterus Fieber (Geocoridae: Hemiptera), fed on Sitotroga cerealella (Olivier) eggs. Egyptian Journal of Biological pest control 27(2):189-194

Velasco-Hernandez MC, Ramirez-Romero R, Cicero L, Michel-Rios C, Desneux N (2013) Intraguild predation on the whitefly parasitoid Eretmocerus eremicus by the generalist predator Geocoris punctipes: a behavioral approach. PLoS One 11:e80679

Xue Y, Bahlai CA, Frewin A, McCreary CM, Des Marteaux LE, Schaafsma AW, Hallett RH (2012) Intraguild predation of the aphid parasitoid Aphelinus certus by Coccinella septempunctata and Harmonia axyridis. BioControl 57:627-663

\section{Submit your manuscript to a SpringerOpen ${ }^{\circ}$ journal and benefit from:}

- Convenient online submission

- Rigorous peer review

- Open access: articles freely available online

- High visibility within the field

- Retaining the copyright to your article

Submit your next manuscript at $\boldsymbol{s p r i n g e r o p e n . c o m ~}$ 